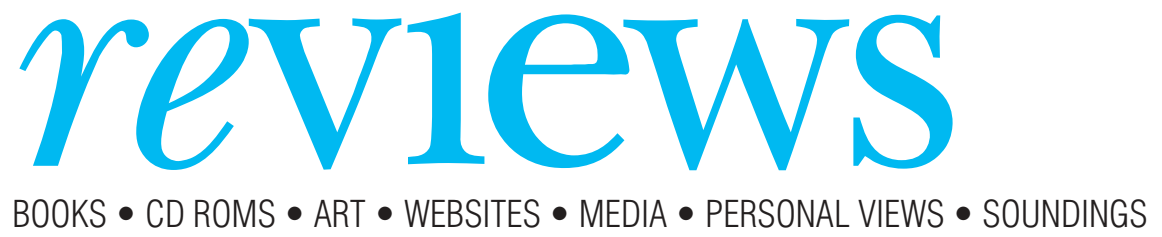

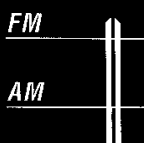

\section{One Man's Medicine}

Three episodes on BBC Radio 4, 6 to 20 August at 9 pm

Producer Beth Eastwood

Programmes also available to download at www.bbc.co.uk/radio4/science/onemansmedicine.shtml

$\mathrm{T}$ he title of Gerald Carson's book about patent medicines, One for a Man, Two for a Horse (Doubleday, about drug doses in women and children, but it did at least intimate that there is variability in responsiveness to medicines, the theme of these three half-hour radio programmes.

Men and women, blacks and whites, old and young-we all differ in the ways in which we respond to medicines. And the sources of variability are legion: differences between pharmaceutical formulations; in understanding and compliance; in drug disposition (pharmacokinetics) and pharmacological responses (pharmacodynamics); in the ways in which variable kinetics and dynamics are translated into therapeutic and
Rating: $\star ; \star \star ; \star \star \star$ 1961), did not tell us what its author thought

adverse outcomes; in physiological and disease interactions with medicines; in the other medicines that we take; and in what we eat, drink, and smoke. The processes are complex, genetic, and environmental, and often unpredictable. And any doctor who wants to be a good prescriber would do well to try to understand them. Ideally, so too should patients. Or at least it would help if they were made aware just how complex the processes are.

But this series started off badly, with a string of wrong, dubious, or incomprehensible statements about a farrago of examples, tumbling over each other without apparent logic. Here is a small sample: "drugs are not often completely ineffective, they're just slightly ineffective"; bleeding from a "standard" dose of warfarin "couldn't have been predicted"; and "women lack an enzyme in the stomach that breaks alcohol down." Random examples about how the pharmaceutical industry and British doctors have neglected interindividual differences in response to medicines compounded the confusion.

It seems that every broadcast dealing with drugs must have a political agenda. And that seemed to be the problem with the first programme. The second, however, vitiated this view by starting to provide a better balance between highlighting the differences between individuals and clarifying the problems that drug developers and pre-

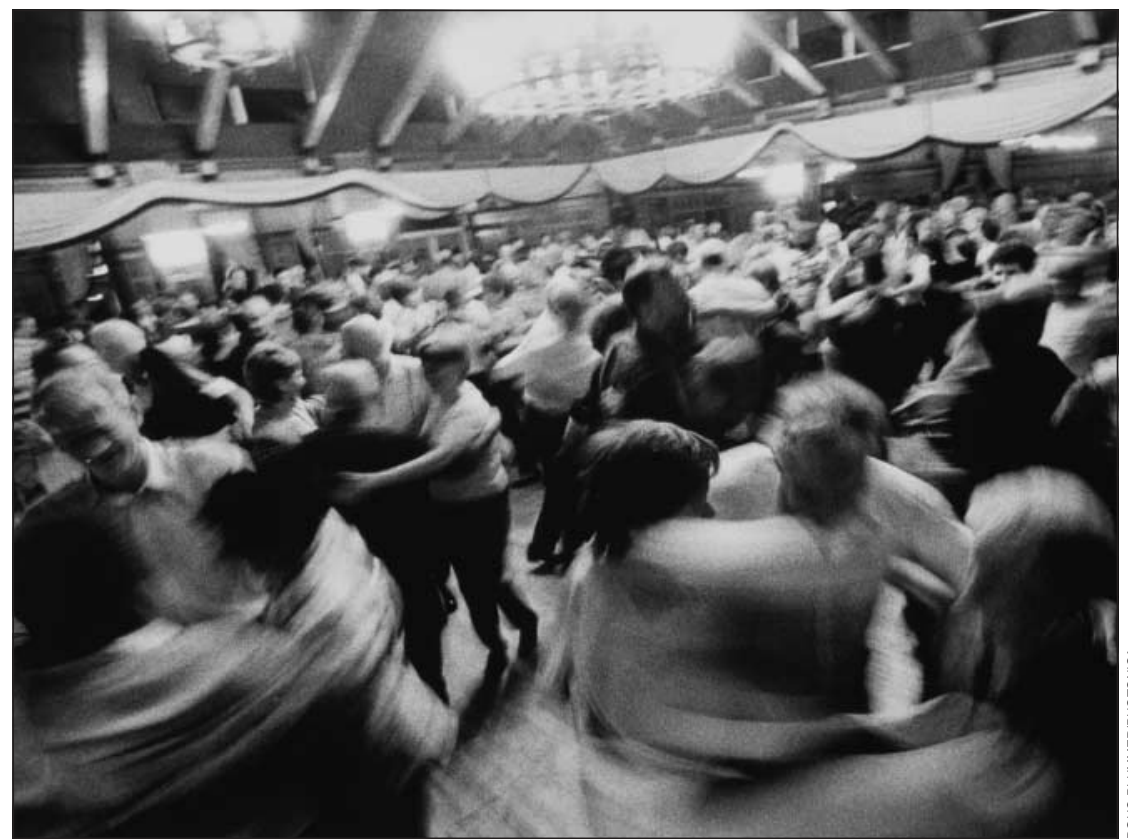

The human population is diverse: one size drugs will not fit all scribers face in dealing with those differences. With judicious re-editing a single really informative programme could be made.

The third programme was the best of all. The potential value of the genomic revolution in relation to drug therapy has been grossly hyped, but here the issues were clearly stated and put into perspective, stressing the polygenicity of most drug effects and the balancing role of environmental factors. The idea that within five or 10 years doctors in their surgeries, or even patients in their homes, might be able to carry out a test that would predict, say, which antibiotic would be useful for an infection was not perhaps sufficiently debunkedwhat, for example, of the genomics of the infecting organism?-but the warning note at the end not to hold your breath was cautionary enough.

There is a real problem here. Women do differ from men-for example, their risk of cardiac arrhythmias from QT interval prolongation is greater. Black people do differ from white people-their hypertension is more resistant to treatment. Elderly people do differ from younger adults-they are more susceptible to the physiological changes that medicines can cause. And, perhaps the most pressing problem of all, children differ from adults in many ways that have not been well studied; and younger children differ from older. But even when there are differences they are not always predictable, and each drug must be studied in depth to find the answers. Drug companies, however, do not find it profitable to do so.

Perhaps, as an incentive, the patent life of a compound, instead of being fixed, should vary according to the amount of information the company provides before marketing. Along similar lines to One for $a$ Man, Two for a Horse.

Jeff Aronson clinical pharmacologist, University of Oxford jeffrey.aronson@clinpharm.ox.ac.uk

Competing interests: I am not a woman, but I am a member of an ethnic minority and I feel more elderly every day. My membership of the Medicines Commission should not imply that my views are shared by other members of the commission or by the Medicines and Healthcare Products Regulatory Agency.

Items reviewed are rated on a 4 star scale ( $4=$ excellent $)$ 


\section{NETLINES}

- A substantial collection of free online medical textbooks is available from the e-library in Scotland (www.elib.scot.nhs. $\mathrm{uk} /$ weblibrary.asp? $\mathrm{cat}=$ Books). The site consists of one long page, but for ease of navigation there is a quick jump tool in the form of a drop down box. The first few sections are mainly devoted to library catalogues, with the links to the books taking up the rest of the page. There are enough subject areas here, from AIDS and HIV to ophthalmology, to interest a wide selection of surfers.

- The Cincinnati Children's Hospital Medical Center has produced the Heart Center Encyclopedia, an elegant and user friendly site aimed at patients and their parents (www.cincinnatichildrens. org/health/heart-encyclopedia/ default.htm). It is full of easily accessible information about paediatric cardiac diseases. There is a printer friendly option and pages can also be emailed to friends. Health professionals not familiar with paediatric cardiac issues may also find this a treasure trove of information. This is an excellent model for other organisations wanting to produce patient-oriented sites that will also interest health professionals.

- Work is under way in the United Kingdom to extend prescribing responsibilities to nurses and pharmacists, in partnership with doctors (so called supplementary prescribing). The Department of Health has produced a site that defines this initiative, explains the background to it, and provides a list of contacts (www.doh.gov.uk/

supplementaryprescribing/index.htm). The site also contains other features such as a what's new section and the ubiquitous but welcome frequently asked questions.

- From Canada comes a neatly laid out information portal about the West Nile virus (www.traqprogram.ca/

wnv-contingencies.asp). Although much of the information here is Canada oriented, there are general and international sections that give it more global appeal. This is an up to date and lively site.

- The internet is an ideal medium on which to publish a collection of clinical guidelines. The website of the Medical Journal of Australia has created a links page of such guidelines on subjects from aboriginal health to rheumatology (www.mja.com.au/public/guides/ guides.html). The page is clearly set out, with the title of each guideline forming the hypertext link to the full guideline. The newest guideline is listed first in each category. This archive can make a useful reference source.

Harry Brown general practitioner, Leeds DrHarry@dial.pipex.com

We welcome suggestions for websites to be included in future Netlines. Readers should contact Harry Brown at the above email address.

Staying Alive: A Family Memoir

Janet Reibstein

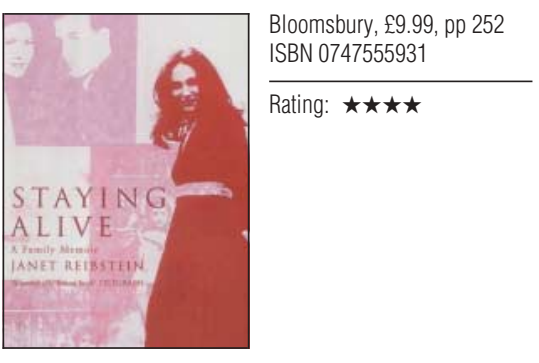

$\Upsilon$ his is a very brave book, and a good read for professionals caring for families with a high risk of breast cancer. This intimate family story explores the dynamics of a cancer (or precancer) diagnosis in not just one beloved relative but five women in a family: the author-who was found to have many individual primary sites of carcinoma in situ after prophylactic surgery-her mother, two aunts, and a cousin.

The story highlights the uncertainty about the age at which a woman who has genetic susceptibility for breast cancer may develop breast disease, whether or not bilateral cancer develops. Reibstein is an academic and a psychotherapist, and she eloquently describes her varying emotionsincluding anger, fear, and, at times, despair. This is not a sentimental "poor me" tale but an honest account of personal experiences. I found it particularly moving to read about poor Aunt Mary, who didn't let anyone in the family know that she had a lump. Indeed

\section{The Visit of the \\ Royal Physician}

Per Olov Enquist, trans Tiina Nunnally

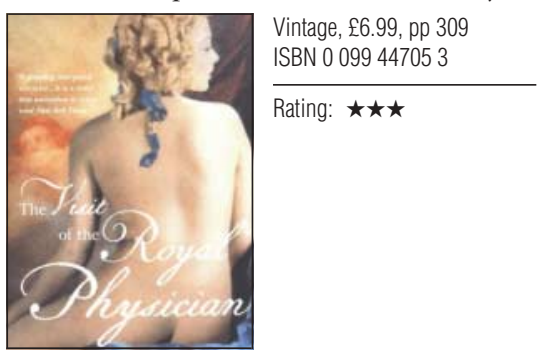

$\mathrm{T}$ he 16-year-old son of King Frederik $\mathrm{V}$ of Denmark succeeded his father as Christian VII in January 1766. He suffered from delusions, was prone to outbursts of violent behaviour, and exhibited repetitive movements under stress, yet spoke three languages and corresponded with Voltaire, who wrote a well known poem in his honour.

In November of that year, 13-year-old Princess Caroline Mathilde, youngest sister of George III of England, was dispatched to Copenhagen to marry Christian. The marriage was consummated by a single visit from the terrified king five months later, which produced a male heir. she kept it secret to avoid bothering anyone-until it was no longer possible to hide the seeping tumour.

Reibstein gives a moving account of the effect of the illness on her remarkable mother, a poet: her ups and downs, her determination to live, and the effect that the diagnosis had on Reibstein's father. Fortunately, Reibstein lightens the load with humorous snippets of American Jewish family life, including the dynamics of the relationship between mother and daughter.

Times have moved on since Aunt Fanny's breast cancer was diagnosed in 1947, when she was a beautiful young woman in her early 30 s with everything to live for. The horror of the surgery and follow up treatment is a reminder of a history best forgotten. The possibility of preventive surgery, despite concerns about body image and the residual risk of cancer, is a considered choice for women such as Reibstein. She harshly describes her metaphorical enemy, "my breasts," saying "soon I will defeat them and take charge" by having prophylactic surgery.

Although Reibstein presents the medical teams as caring and deeply concerned, there are times when one gulps at the inhumanity of some of the professionals she encountered. Reibstein has moved on since her mother died and has hope for the future. However, she reminds us that professionals need to be sensitive when churning out their requests for information.

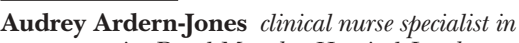
cancer genetics, Royal Marsden Hospital, London Audrey.Ardern-Jones@rmh.nthames.nhs.uk

Worried by the monarch's mental state, the court appointed a hitherto obscure doctor named Johann Friedrich Struensee, "a specialist in cupping," to look after him. He and Queen Caroline soon took over the running of the country and became lovers. When a child was born in 1791 no one had any doubt who the father was.

Rumours spread that the king was being held captive by Struensee and "the English whore." On 17 January 1772 a party of grenadiers seized Struensee and Enevold Brandt, "the King's nursemaid," and the two were sentenced to death.

The queen, angry and defiant, was exiled to one of the British king's palaces at Celle. There she died suddenly in 1775 aged 23, some say poisoned. Ove Høegh Guldberg, tutor to the king, became prime minister, and retained power for 12 years, while the king became increasingly deluded. The final irony is that nearly every European royal house can trace its lineage back to Struensee through his illegitimate daughter.

Enquist chooses a novelistic approach to a real life scandal that engrossed 18th century Europe. His account reads at times like a film script.

Alex Paton retired consultant physician, Oxfordshire 
PERSONAL VIEW

\section{Contrasts}

$\mathrm{T}$ hursday morning starts, as any other, with an 8 am ward round of the postoperative patients. There are only three "survivors" to see, as the usual lack of beds meant the operating list had been severely cut. The ward sister warns that next week's operating list will also have to be reduced, because the department's “overspend" has resulted in eight beds closing. At 9 am the outpatients' clinic starts. Patients are waiting to be seen, and the medical students are eager, but many of the patients' medical records are unavailable and the electronic patients' records system is "down." We have to decide whether to ask the patients to book another appointment or to try to sort out their problems without their investigation results. Some women have come a long distance and, naturally, are concerned or angry. "I am so sorry to keep you waiting" seems trite after its 10 th repetition.

The clinic finishes at $1 \mathrm{pm}$. Having dealt with the urgent queries and correspondence, and feeling thoroughly demoralised, I drive to Heathrow and board a plane for the United States. Eight hours later, feeling very virtuous, as I have read half of a thesis I am examining and written reviews on two manuscripts submitted for publication in journals, I alight at Chicago to be met by a limousine and taken to a modern conference hotel. I enjoy stimulating discussions over dinner with professional colleagues from around the world.

Friday morning starts early, as we have much to discuss at the global advisory board meeting of a large drugs company that will launch a new drug early next year. At the end of the day we all feel something has been accomplished. I am thanked by a vice president of the company and assured that my comments are valued, so much so that he suggests upgrading my flight home to first class so I "have a good night's sleep."

Monday starts as any other. At 7 am I see the preoperative patients in the private hospital I work in. They have all been properly prepared for surgery that day. The operating list starts at precisely $730 \mathrm{am}$, and no delays occur. The anaesthetist and theatre staff are cheerful, the list runs smoothly, and we all leave the hospital in good time to resume our "other lives."

On arrival at my "three star" NHS teaching hospital I am not surprised when the ward sister says that I must "prioritise" my operating list to ensure that there are no cancellations the next day (even though more beds might be available by then). But how can I prioritise on clinical grounds when all the procedures are "elective"? Should I really have to decide between a woman who has put her children into care for her operation, a woman who has come from the other side of the country because she has already had several failed procedures locally, and a woman whose operation has been cancelled twice before? Surely these are administrative decisions, not clinical ones? All I can say to the women is that it is not in my power to provide beds for all the women under my care who need surgery.

Tuesday starts with a delay in getting the first patient to the operating table, because the operating list starts at $8 \mathrm{am}$, and so does the nursing "shift." The anaesthetist is irritated because the operating list is not as published (only three beds were available for seven cases). The theatre staff are annoyed that their afternoon will be spent being redeployed to other theatres because of the curtailed operating list, the trainees are upset because they won't see much surgery, and the medical students don't understand why there is so little clinical teaching.

Thursday again, and nothing has really changed. Again I need to apologise to patients for missing notes or because their investigation results are not available. A different set of specialist registrars need support, and a new group of medical students are bewildered by the clinical conditions. But, oh, how privileged I am! I can again escape- this time to join the scientific committee of an international multidisciplinary society to select abstracts for presentation at the annual scientific meeting. My opinion is valued and my suggestions are influential.

As a strong supporter of the NHS I realise that without my base in a teaching hospital much of the intellectual stimulation and escape that I so value would be impossible. But many hospital consultants can't escape and must suffer the daily problems in the current NHS for all of their working lives. They may complain about their pay, the long working hours, or inferior facilities, but their main problem is that they feel grossly undervalued and unable to fulfil the roles they were trained for. Perhaps some who intended to devote their working lives to the NHS could be forgiven for thinking that defecting to industry or private practice might offer a better quality of life?

Competing interests: I receive money for research, lecturing, and educational purposes from Bioplasty Inc, Yamanouchi, Eli Lilly, Ethicon (Gynecare), Pfizer, Laborie, and BioControl (BCM) Ltd.

Linda Cardozo professor of urogynaecology, Londonlcardozo@compuserve.com
SOUNDINGS

\section{Growing algorithms from seed}

A couple of weeks ago, along with half the trade across the United Kingdom, I braced myself for our annual influx of brand new preregistration house officers. Last month's students became, however tentatively, young colleagues on the ward.

The feast of the innocents passed uneventfully, as it usually does. No serious cause for concern and, as always, a process of sussing out the new batch: who's good, who's worried, who might just turn out to be a worry in their own right.

Worry comes into it a lot, as anyone who looks back honestly at their own first weeks in paid medicine will admit. So much is new and uncertain, so little to be taken for granted. Anything from a drug dose to a consultant's mood swing can bring disaster, and each patient is an unknown, so we worry.

We don't go on like that. We learn the basics, and as the years go by we worry less and even think less. The simple truth-and very much not for circulation beyond the strict confines of this column-is that most consultants don't have to think very much at all.

Instead, and each within our own specialties, we run every new case through a subcortical algorithm, built up over years of experience in the diagnosis, management, and outcomes of the common, the common variations, and the rare. To run a personal, continuously developing but essentially pre-conscious programme of "fine-grained probabilistic clinical reasoning," as a researcher once helpfully described it to me, is not lazy or careless, but rather efficient and generally reliable: the hallmark of the seasoned professional.

Of course we must always be open to the truly exceptional, the case that-less than once a year or more-should rouse us from thalamic medicine. Not good to miss the things sent to try us; and hence of course our disproportionate zeal for the gee-whiz grand rounds case: the ordinary looking chap who turns out to be harbouring a grade 5 fascinoma.

But such stuff is rare, and probably best kept from our youngest colleagues, whose task for the moment is to work and look and listen and read and learn: a lot about what is normal, a great deal about what is common, and how such things are recognised, managed, and turn out. It is an investment for the long term: growing, as it were, one's own algorithms from seed.

Colin Douglas doctor and novelist, Edinburgh 